\title{
SCHELLING, NIETZSCHE E A ARTE TRÁGICA: AFINIDADES ENTRE FILOSOFIAS AFIRMATIVAS ${ }^{1}$
}

\author{
Victor Hugo Mazia ${ }^{2}$ \\ Universidade Estadual de Maringá (UEM) \\ (D) https://orcid.org/0000-0002-4737-0127
}

\begin{abstract}
RESUMO:
Este artigo tem a intenção de mostrar as interpretações que Schelling e Nietzsche fazem acerca da arte trágica. Diante dessas duas filosofias, tentase aproximar alguns pontos de coincidência entre o pensamento dos dois filósofos. Por um lado, Schelling se preocupará em superar a dicotomia liberdade/necessidade para que, enfim, possa afirmar a liberdade. Por outro lado, Nietzsche visa superar o pessimismo e, após tal superação, afirmar a vida. Assim, faz-se notável o fato de que os dois filósofos encontram, na arte trágica, um caminho extremamente positivo, pois ambos os pensadores promovem uma superação e afirmação.
\end{abstract}

PALAVRAS-CHAVE: Schelling; Nietzsche; Arte trágica; Superação; Afirmação.

\section{SCHELLING, NIETZSCHE AND THE TRAGIC ART: AFFINITIES BETWEEN AFFIRMATIVE PHILOSOPHIES}

\begin{abstract}
:
This article intends to show Schelling's and Nietzsche's interpretations about the tragic art. Before these two philosophies attempts to approach some coinciding points between the two philosophers. On the one hand, Schelling cares to overcome the dichotomy freedom/needs so that he is able to affirm the freedom. On the other hand, Nietzsche aims to overcome the pessimism and, after that, affirm the life. Therefore, it is remarkable the fact that the two philosophers find, in tragic art, a path extremely positive, because both authors promote an overcome and affirmation.

\footnotetext{
${ }^{1}$ À Juliana Mazia e ao Ismael Mazia, uma dualidade insuperável.

${ }^{2}$ Mestrando em filosofia pela Universidade Estadual de Maringá (UEM), Paraná - Brasil.

E-mail: victormazia@gmail.com.
} 
KEYWORDS: Schelling; Nietzsche; Tragic art; Overcoming; Affirmation.

A arte trágica esteve, em algumas ocasiões, no centro de determinadas reflexões filosóficas. Se considerarmos, por exemplo, Aristóteles, Hegel, Schiller, Schelling ou Nietzsche, descobriremos quão importante foi a arte trágica para esses pensadores. De fato, ela foi analisada sob a óptica filosófica em inúmeros sentidos. ${ }^{3}$ Contudo, dentre as tantas investigações, será que poderíamos encontrar alguma semelhança entre as análises de Schelling e Nietzsche? É sob essa perspectiva - olhar a tragédia dentro da filosofia, com o intuito de compreender a importância da arte trágica no interior do pensamento de Schelling e Nietzsche - que analisaremos a tragédia.

A princípio, nós precisamos nos perguntar se essa arte teria alguma relevância positiva para a existência, de acordo com a perspectiva de Schelling e Nietzsche. E, em seguida, se seria possível encontrar algum ponto coincidente entre as duas análises: teria a tragédia a mesma importância para esses pensadores?

Assim, para que essa leitura seja empreendida, utilizaremos duas tragédias diferentes: a tragédia de Sófocles chamada Édipo Rei, que servirá para pensarmos a análise de Schelling; e a trilogia de Ésquilo, intitulada Oréstia, que nos auxiliará a pensarmos a importância da tragédia para Nietzsche. ${ }^{4}$ Doravante, passaremos para a tragédia de Sófocles e a interpretação feita por Schelling.

\section{Schelling e o Édipo Rei}

Na tragédia de Édipo Rei, conta-se a história de certo rei que habitava em Tebas e que recebeu uma profecia do oráculo de Delfos. Essa profecia dizia que o seu filho o mataria e se casaria com a rainha (no caso, a sua própria mãe). Dessa forma, o rei e a rainha, em comum acordo, pedem para um pastor que leve o menino para um lugar distante e o mate. O pastor,

\footnotetext{
${ }^{3}$ Temos relatos sobre inúmeras interpretações filosóficas acerca da arte trágica, como é o caso dos desdobramentos da perspectiva aristotélica. Na Poética, o estagirita entende que, ao produzir a Katharsis, a tragédia teria uma importância vital para o povo. Essa interpretação aristotélica promoveu mais de 150 interpretações diferentes acerca do efeito e importância da tragédia. (Cf. BRANDÃO. 1985. p. 12). Com tantas interpretações, podemos sustentar com certa segurança que a tragédia foi explorada de modo profundo dentro da filosofia.

${ }^{4}$ Utilizaremos a tragédia de Sófocles, o Édipo Rei, porque Schelling lança mão da mesma tragédia recorrentemente em Filosofia da Arte (Cf: SCHELLING. 2001. p. 316-327); e usaremos a trilogia Oréstia de Ésquilo porque, dentre os trágicos, Ésquilo é o que exercia melhor essa arte segundo Nietzsche. (Cf.: GT/NT §11-15). Assim, a escolha dessas tragédias se justifica no interior do próprio pensamento de Schelling e Nietzsche, além de conferir a possibilidade de uma maior compreensão das análises dos filósofos.
} 
chegando a um lugar distante, amarra o menino de cabeça para baixo em uma árvore ${ }^{5}$. No entanto, o pastor tendo dó do menino, o leva para Corinto para ser criado por um casal. Esse casal - Pólibo e Mérope - cuida desse menino sem lhe revelar a verdadeira origem. Passado o tempo, o menino recebe a mesma profecia que o pai biológico recebeu do oráculo de Delfos, a saber, que mataria o pai e se casaria com a mãe. Tendo consciência disso, Édipo foge de Corinto por medo de cumprir esse destino cruel que lhe foi profetizado. No caminho de volta do Oráculo, Édipo se depara com alguns viajantes e, por alguma desavença qualquer, ele luta com os viajantes e os mata. Na sua fuga de Corinto para outro lugar, Édipo acaba parando em Tebas. Essa cidade estava passando por grandes dificuldades na época; lá havia uma Esfinge que estava devorando os cidadãos tebanos. Édipo, chegando a Tebas, desvenda o enigma da esfinge, findando com a maldição que assolava a cidade. Como prêmio de sua ação, o forasteiro recebe a coroa de Tebas e se casa com a rainha da cidade.

Com o passar do tempo, devido a um crime terrível, outra maldição ameaça a cidade, isto é, alguém que mora na cidade assassinou Laio, o antigo rei de Tebas. Édipo, portanto, começa a investigar o assassinato de Laio. Quando os homens contam que Laio saiu para consultar o oráculo e não retornou, Édipo começa a pensar na hipótese do antigo governante de Tebas ter sido o sujeito que ele matou na estrada quando voltava do oráculo de Delfos. Ao ouvir as histórias sobre Laio, Édipo aceita e assume para si o homicídio do antigo rei. Ao aceitar o fato de ter matado Laio, Édipo cumpre seu destino, matando o próprio pai e casando-se com a mãe. Doravante, Édipo fura os seus olhos e vai para Colono (cf. SÓFOCLES. S/D).

A partir dessa tragédia edipiana, Schelling parece ter a intenção de superar a antinomia liberdade/necessidade, já levantada por Kant, em Crítica da Razão Pura. Nesse sentido, Schelling afirma: "O essencial da tragédia é, portanto, um conflito real entre a liberdade no sujeito e a necessidade, como necessidade objetiva, (...)" (SCHELLING. 2001. p. 316). Assim, como podemos entender esse problema da dualidade liberdade/necessidade? De acordo com Kant, na terceira antinomia, encontramos um conflito entre liberdade e causalidade. Se concordarmos que o mundo é regido por causa e efeito, então teríamos que concordar que uma causa precisa, necessariamente, de outra causa anterior a ela, e assim sucessivamente. Isso deveria nos levar a uma causa primeira que não é causada por nada. Todavia, não há essa causa.

Portanto, a causalidade da causa, pela qual qualquer coisa acontece, é em si qualquer coisa acontecida, que, por sua vez,

\footnotetext{
${ }^{5}$ Por ter sido amarrado pelos pés e esses terem inchado, Édipo recebeu seu nome, ou seja, pés inchados: "Os soberanos de Corinto criaram e educaram o menino, como se fosse seu filho, tendo-lhe dado o nome de Édipo, que quer dizer pés inchados, em consequiência da inflamação provocada pelas cordas que o prendiam na árvore” (BRANDÃO. 1984. p. 39).
} 


\begin{abstract}
pressupõe, segundo a lei da natureza, um estado anterior e a sua causalidade; este, por sua vez, outro estado ainda mais antigo, e assim sucessivamente. Se tudo acontece, portanto, unicamente pelas leis da natureza, haverá sempre um começo subalterno, nunca um primeiro começo, e não há portanto integridade da série pelo lado das causas provenientes uma das outras. Ora, a lei da natureza consiste em acontecer sem uma causa suficiente determinada a priori. Assim, a proposição, segundo a qual toda a causalidade só é possível segundo as leis da natureza, contradiz-se a si mesma na sua universalidade ilimitada e não pode, pois, considerar-se que esta causalidade seja a única. (KANT. 2001. p. 425).
\end{abstract}

Deste modo, uma causa implica em outra e em outra e, assim, sucessivamente. Ou seja, o homem é determinado em suas ações e não há espaço para a liberdade. Se há uma necessidade causal na natureza, então não há liberdade. Logo, se não há liberdade no mundo, então não há ações morais.

Por outro lado, se nós defendermos a ideia de uma natureza sem causalidade, então teremos que admitir a impossibilidade de fazer ciência ${ }^{6}$. Assim, a dualidade liberdade/necessidade encerra um problema que, aparentemente, parece ser insolúvel. Para Schelling, a tragédia é um agente unificador entre liberdade e necessidade. Assim, como podemos ver essa conciliação na tragédia? Como a arte trágica pode superar essa dualidade? Ora, não teria Édipo sucumbido frente ao seu destino e perdido sua liberdade? Para responder tais questionamentos, Schelling afirma: "Mas que esse culpado inocente assuma voluntariamente a punição, isso é o sublime na tragédia; somente por meio disso a liberdade se transfigura em suprema identidade com a necessidade" (SCHELLING. 2001. p. 320).

Édipo está em Tebas como rei sofrendo as dificuldades de uma maldição que sua cidade enfrenta. Dentre as pessoas que Édipo chama para tentar identificar o porquê da maldição, ele encontra uma resposta: a causa da maldição é um parricídio realizado no passado. Na tentativa de descobrir o autor de tamanho ato de violência, ele começa a descobrir a sua verdadeira origem. Diante dessa verdade, a hipótese dele ter encontrado o antigo rei de Tebas e tê-lo matado se mostra possível e provável. Porém, isso não explica o parricídio cometido, pois Édipo não se via como o filho de Laio e sim como filho de pais que residiam na cidade de Corinto. Sua mulher, no entanto, diz sobre o seu antigo filho que supostamente estava morto e que ela mandara matar em função de uma profecia mandada pelo Oráculo de Delfos. Coincidentemente, Édipo se lembra de ter recebido a mesma profecia em Corinto. Assim, eles chamam o sujeito que deveria ter matado o

\footnotetext{
${ }^{6}$ Embora Kant tenha tornado manifesto o problema da dualidade liberdade/necessidade, ele propõe uma solução em sua obra Crítica da razão pura. Contudo, nosso objetivo é mostrar a apropriação que Schelling faz desse problema e, assim, mostrar como ele tenta superá-lo com a arte trágica.
} 
filho de Jocasta e ouvem a confissão de que ele não realizou tal ação, mas deu a criança para casais de Corinto. Tudo estava explicado: Édipo acredita ser o menino que não havia sido assassinado, admite que o viajante que matara era seu pai e assume esse papel. Édipo escolhe, livremente, ser o autor do crime, ele aceita o seu destino, aceita a sua vida como sendo o autor de tal ato e não foge da sua condição. Édipo suportou voluntariamente seu castigo inevitável, demonstrando assim a declaração da sua liberdade. Ele aceita o seu destino e é dizendo sim à sua fatalidade que Édipo demonstra a vitória da sua liberdade. Como Schelling afirma: "O maior pensamento e a maior vitória da liberdade é suportar voluntariamente também o castigo por um crime inevitável, para assim, na perda de sua própria liberdade, demonstrar essa mesma liberdade e sucumbir, porém, ainda com uma declaração de sua vontade livre" (SCHELLING. 2001. p. 318).

$\mathrm{Na}$ óptica de Schelling, a tragédia tem a capacidade de dissolver a dualidade liberdade/necessidade. Por conseguinte, o herói, ao escolher voluntariamente o caminho imposto pelo seu destino, supera a necessidade. Se Édipo escolhe voluntariamente assumir o papel de parricida, então não podemos falar da potência da natureza como agente ativa dessa situação, mas podemos afirmar que Édipo está realizando um ato da liberdade. Por isso, ele não é totalmente determinado, pois ele, ao escolher voluntariamente o caminho que o destino o força a trilhar, afirma sua liberdade.

Sendo assim, conforme Schelling, liberdade e necessidade estão unidos na tragédia, uma vez que o herói, ao escolher o seu destino, acaba afirmando a sua liberdade e, ao mesmo tempo, cumpre o seu destino. É nessa superação da dualidade liberdade/necessidade, chamada por Schelling de indiferença, que encontramos a importância da arte trágica para o filósofo alemão. Portanto, diante da análise de Schelling, a imposição do destino não exclui a liberdade humana, reduzindo a existência dessa dualidade em uma unidade.

\section{Nietzsche e Oréstia}

A trilogia de Ésquilo é uma tragédia que, apesar de levar consigo o nome de tragédia, como acontece em Sófocles e Eurípides, ela não carrega a mesma estrutura das demais ${ }^{7}$. Aliás, todos os três tragediógrafos acabam por criar uma estrutura diferente (cf. BRANDÃO. 1984. p. 42-44).

\footnotetext{
${ }^{7}$ Brandão nos auxilia a entender a diferença estrutural entre as tragédias de Ésquilo e Sófocles: "Se Ésquilo concebeu seu teatro como a representação profundamente religiosa de um evento lendário, Sófocles faz de sua tragédia o desenvolvimento normal de uma vontade e de um caráter humano numa situação determinada. Ésquilo, já que seu teatro é uma teomorfisação e suas personagens são antes 'heróis', mais gigantes que seres humanos, elaborou seu drama como uma luta desesperada entre as trevas e Erínias, entre Hades e o Olimpo. (...) Em Sófocles, ao revés, o teatro é essencialmente antropocêntrico e teosférico,
} 
Ésquilo inicia sua trilogia com a declaração de um guarda que espera há dez anos o sinal de fogo que indicaria a vitória dos gregos contra os troianos. Deste modo, apesar da alegria dos gregos com a mensagem do fogo, eles se lembraram do sacrifício de Agamêmnon, que sacrificou sua filha Efigênia. Ao voltar à sua casa, a Cólera, encarnada na mulher de Agamêmnon, o esperava. Clitemnestra tinha visto a filha ser sacrificada e, depois de dez anos, ela ficara esperando a volta do marido para realizar o assassinato dele. Quando Agamêmnon chega à sua terra, sua esposa o assassina com ajuda de seu amante Egisto.

Depois desses acontecimentos, envolvendo esses três personagens, outra personalidade aparece, a saber, Orestes. O oráculo de Apolo lhe havia mostrado que os piores sofrimentos lhe aguardavam caso Orestes não vingasse a morte do pai, tendo que matar tanto Egisto quanto a própria mãe. Entretanto, depois de Orestes ter matado a mãe e seu amante, o matricida não tem tempo de chegar ao santuário, pois as Eríneas surgem, querendo derramar o seu sangue. Para as Eríneas, o matricídio é um crime inexpiável e Orestes, que apesar de chegar ao templo, chega ao templo totalmente conturbado.

Agora, na terceira parte da trilogia, Dentro do templo que Orestes havia chegado, há um "tribunal" em que Apolo tenta defender Orestes das Eríneas. Seu argumento central utilizado para acalmar as Eríneas é dizer que foi tudo da vontade de Zeus. Porém, isso não é o bastante para aplacar a fúria das deusas. Em uma situação em que os pratos da justiça não pendem nem para a direita e nem para a esquerda, Atena intervém a favor do matricida. Ela diz que somente na medida em que todos os argumentos tanto de deuses quanto de homens - forem analisados, então o tribunal encontrará a justiça. Assim, Orestes é liberto pelo veredicto de que ele não agiu por sua vontade, mas para cumprir a profecia de Apolo. As Eríneas se sentem completamente lesadas por não poderem prejudicar o matricida. Atena intervém novamente, garantindo uma posição de honra entre os gregos para as deusas matriarcais. Agora as Eríneas não serão mais conhecidas por atormentar os mortais e vingar os crimes de sangue, elas se tornaram as Eumênides (as benevolentes), tendo a função de cuidar da prosperidade de Atenas, a fim de reinar a justiça entre os gregos (ÉSQUILO. 2000). A questão mais uma vez vem à tona: qual a importância da arte trágica para Nietzsche? Ela teria algum vínculo com a condição existencial do homem? E consegueríamos aproximar as análises de Nietzsche e Schelling?

quer dizer, o herói é dotado de vontade, de uma vontade livre para agir pouco importa quais sejam as consequiências, e os deuses agem, mas sua atuação é a distância, por meio de adivinhos e de oráculos: Tirésias e o Oráculo de Delfos têm sempre um encontro marcado com os heróis de Sófocles" (BRANDÃO. 1984. p. 42-43). Essa diferença entre Ésquilo e Sófocles é crucial para entendermos a preferência de Nietzsche por Ésquilo, pois, conforme Brandão, o elemento racional, criticado por Nietzsche, é maior em Sófocles. 
Nietzsche propõe, em $O$ Nascimento da tragédia, uma justificação da existência baseada nos efeitos da arte trágica: "pois somente como fenômeno estético podem a existência e o mundo justificar-se eternamente" (GT/NT §5). Desde o primeiro momento da obra nietzschiana, podemos perceber que o filósofo reflete sobre a condição existencial do homem a partir da Grécia (cf.: MACHADO. 1985. p. 26). O grego tinha uma aguda sensibilidade para o sofrimento, permitindo-lhe uma condição diferenciada da existência (cf. NT/GT §4). As famosas sabedorias populares proporcionavam esse contato com o sofrimento que os gregos sentiam em demasia - como é o caso dos efeitos produzidos pela sabedoria de Sileno ${ }^{8}$. Por isso, os gregos tinham uma grande necessidade da arte, sobretudo da arte que embelezava a vida e mascarava os horrores da existência (arte apolínea). Esse embelezamento ajudava o homem a encarar a vida pessimista mostrada pelas sabedorias populares. Em outras palavras, a arte tornava a vida possível e desejável. Os gregos, através da criação dos deuses olímpicos - criação esta fruto da arte apolínea -, conseguem mascarar o sofrimento contido na sua existência, potencializando os poderes humanos nas figuras dos deuses. Deste modo, a arte é propriamente formadora da religião grega e essa ajudava, através da retratação dos deuses, a querer viver. Os deuses olímpicos e todo o seu mundo olímpico exprimiam a exaltação da natureza humana, exprimiam o embelezamento exacerbado da vida, o retrato do mundo de forma exagerada. A arte e a religião eram intimamente ligadas, ao ponto de os deuses gregos serem belos e não moralmente corretos, eles não eram necessariamente bons e verdadeiros, mas eram belos.

Assim, a função da aparência era a de mascarar a essência verdadeira e dilacerante da vida, expressa, por exemplo, por Sileno. Por isso, a aparência impedia que as verdades reais do mundo pudessem eclodir. Nesse prisma, o belo garante a vontade de viver, mantém a vontade de existir.

Em contrapartida, a arte apolínea não passa de pura dissimulação da essência da natureza humana, encobrindo a única coisa verdadeiramente existente (Wahrhaft Seiende), chamado por Nietzsche de Uno primordial (Ur-eine). É por isso que o homem, frente à essência do mundo, tem necessidade da criação da bela aparência para poder ter uma relação com o Uno primordial sem aniquilar a sua própria existência. A arte apolínea é a única capaz de transfigurar a essência em uma realidade possível de ser vivida e experienciada. De acordo com Nietzsche:

\footnotetext{
${ }^{8}$ As sabedorias populares apontavam para uma realidade cruel e negativa. A sabedoria de Sileno, explicitada por Nietzsche, mostrava para os gregos que a vida não valia a pena, elevando a perspectiva pessimista da vida ao mais alto grau. Sileno exclama: "Raça de efêmeros, filhos do acaso e da pena, por que me obrigar a dizer o que não tens o menor interesse em escutar? O bem supremo te é absolutamente inacessível: é não ter nascido, não ser, nada ser. Em compensação, o segundo dos bens tu podes ter: é logo morrer." (GT/NT § $3)$.
} 
com efeito, quanto mais percebo na natureza aqueles onipotentes impulsos artísticos e neles um poderoso anelo pela aparência (Schein), pela redenção através da aparência (zum Erlostwerden durch den Schein gewahr), tanto mais me sinto impelido pela suposição de que o verdadeiramente existente (Wahrhaft Seiende) e Uno-primordial (Ur-eine), enquanto o eterno-padecente e pleno de contradição necessita, para sua constante redenção (Erlosung), também da visão extasiante, da aparência prazerosa (...) (GT/NT §4).

Por isso, a apologia da arte se torna tão necessária para Nietzsche, pois ela consegue encobrir uma perspectiva que ameaça a própria vida ${ }^{9}$.

Com efeito, a arte trágica possui, para Nietzsche, os dois elementos necessários para possibilitar uma cultura afirmativa. Tanto a beleza mascaradora do verdadeiramente existente, quanto a realidade nua e crua, insuportável ao homem e plena de contradição, estão presentes na arte trágica. O herói, elemento apolíneo da arte, representaria o indivíduo que luta para permanecer vivo, enquanto o coro, elemento dionisíaco, cantaria as verdades do Uno primordial. Em outras palavras, o homem, mediado pela bela aparência, tem contato com as verdades do Uno primordial e, mesmo assim, essas verdades não o destroem, pois a beleza torna todas as verdades suportáveis, potencializando a vida.

Entretanto, como podemos identificar esses elementos descritos por Nietzsche na tragédia Oréstia? Nas obras de juventude, Nietzsche sustenta uma tese inovadora: a tragédia teria advindo do espírito da música. $\mathrm{O}$ coro, segundo Nietzsche, é a única personagem que revela as verdades essenciais da natureza, em consonância com as sabedorias populares gregas. O coro é o único elemento fixo na trilogia (cf. RUBIRA. 2009. p 249-261). Note que,

\footnotetext{
9 Vattimo dirá que os gregos formaram duas formas de criação para se proteger do sofrimento. Para essas criações, Gianni Vattimo dá dois nomes: a máscara boa e a máscara má. A máscara má é aquela criação que tem como fundamento, como estimulante para a ação do homem o medo da essência do mundo, do Uno Primordial. Assim, a criação tem o intuito de esconder totalmente a essência do mundo. Segundo Gianni Vattimo, Nietzsche mostra essa criação artística, que foi gerada pelo medo, no texto Verdade e Mentira no Sentido Extra-Moral, tendo o Estado moderno como um lugar que demonstra a reclusão do dionisíaco. Esse Estado moderno como sendo a criação para evitar a máxima bellum omnus contra omnibus, é uma forma da arte apolínea - arte que mascara - se sobressair totalmente à arte dionisíaca. A outra máscara, que é a máscara boa, entende o Estado da idade trágica dos Gregos, antes de Alexandre, como uma forma da qual o homem não tenta se libertar do dionisíaco em função do medo que ele tem da essência do mundo, mas liberá-lo como condição de vida poetizante através da máscara apolínea. Por isso, há uma capacidade de mascarar a existência tendo o medo como motivador para isso - máscara má -, e outra forma de mascarar a existência pelo querer o dionisíaco e liberá-lo aos poucos, necessitando assim do apolíneo para não sucumbir frente ao dionisíaco puro - máscara boa. A função da arte na primeira fase de Nietzsche é, através da liberação da verdade com a ajuda da mentira, isto é, liberação do dionisíaco com a ajuda do apolíneo, estimular o homem a querer viver. (VATTIMO. 1989. p. 43-65).
} 
na primeira parte da trilogia, as personagens principais são Agamêmnon, Clitemnestra, Cassandra e Egisto. Na segunda parte, as personagens são Orestes, Eléctra, Clitemnestra e Egisto. Na terceira, e última parte, estão Orestes, Apolo e outros deuses. Assim, se considerarmos a trilogia por inteira, então notaremos uma mudança entre os protagonistas, sendo o coro o único elemento fixo. Todavia, na primeira parte, o coro é formado pelos anciãos de Argos; na segunda, é um coro formado por cativos; na terceira, o coro é formado pelas Erínias e Eumênides. Então, como poderíamos concordar com Nietzsche que o coro é o único elemento fixo na tragédia? O coro é, em toda a trilogia, formado pelos servidores de Dioniso: "a tragédia surgiu do coro trágico e (...) originariamente ela era só coro e nada mais que coro" (GT/NT §7). Desta maneira, para explicar que a tragédia nasceu do coro e que esse coro é constituído por seguidores de Dionísio anunciadores da essência e da verdade do mundo, Nietzsche afirma que na natureza existem dois impulsos distintos, a saber, o apolíneo e o dionisíaco:

A partir destes elementos, a tese nietzschiana de que, inicialmente, 'a tragédia era só coro e nada mais que coro', ganha clareza. O poeta trágico, o qual para Nietzsche 'é ao mesmo tempo um pensador religioso’ (GT/NT §9) aproveitou o coro dionisíaco que entoa todos os seus cantos em homenagem ao seu deus, e a partir dele desenvolveu a tragédia. Na verdade, segundo Nietzsche, os antigos gregos compreendiam a cena e o desenrolar da ação trágica não como algo em si, mas como visão do coro trágico. É o coro trágico quem produziria, em imagens apolíneas, todo o desenrolar da cena. No caso, portanto, da trilogia Orestéia, a única realidade em si é o coro trágico, e toda a ação trágica, com o assassinato de Agamêmnon, e depois com o matricídio que Orestes vem a cometer, é apenas visão do coro trágico para mostrar que os indivíduos, e entre eles os heróis, nada são individualmente diante do vir-a-ser do mundo, mas que apesar do destino trágico ao qual estão submetidos, a vida sempre renasce a partir da destruição. (RUBIRA. 2009. p. 259).

Por fim, na tragédia grega, o elemento dionisíaco (coro) revela uma realidade insuportável ao homem, podendo ser percebida nas mudanças que os heróis estão submetidos, isto é, na morte e na destruição próprias da vida. E, ao mesmo tempo, o dionisíaco mostra como "a vida sempre renasce a partir da destruição" (RUBIRA. 2009. p. 259). Essa é a importância da tragédia para Nietzsche: que mesmo em meio ao aniquilamento da vida, o embelezamento da existência ainda é possível. Com o impulso apolíneo, o homem cria sentido para sua vida e mesmo sabendo da sua condição mortal, se alegra por poder retornar ao Uno primordial. Deste modo, nem a morte potencializaria um desgosto pela vida, pois o homem sabe que pertence a algo maior que ele, isto é, ao Uno primordial. 


\section{Considerações finais}

Enfim, será que poderíamos achar um ponto em comum entre as análises de Nietzsche e Schelling? Parece haver uma semelhança entre o pensamento dos dois filósofos: no interior do pensamento de ambos, a tragédia tem a função de afirmar algo. Em Schelling, a tragédia tem a função de afirmar a liberdade, superando a dualidade liberdade/necessidade. Em Nietzsche, a tragédia afirma a vontade de viver, superando o pessimismo até então intrínseco a existência. De um lado, Schelling mostra, através da arte trágica, que o homem tem condições de afirmar a sua liberdade, podendo superar a dualidade liberdade/necessidade. Do outro lado, Nietzsche mostra por meio da arte trágica, que o homem tem condição de afirmar sua existência, superando o pessimismo e o nojo da existência. Portanto, os dois filósofos encontram na arte trágica uma positividade: eles encontram uma afirmação - seja da liberdade ou da vontade de viver - e os dois conseguem realizar uma superação - seja da dualidade liberdade/necessidade ou do pessimismo -, permitindo uma aproximação.

\section{Referências bibliográficas}

BRANDÃO, Junito de Souza. Teatro grego: Tragédia e comédia. $8^{\mathrm{a}}$ ed. Petrópoles: Editora Vozes, 1985.

de Janeiro: Editora Vozes, 1984.

Teatro grego: Tragédia e comédia. $3^{\mathrm{a}}$ ed. Rio

ÉSQUILO. Oréstia: Agamêmnon, Coéforas e Eumênides. Tradução: Mário da Gama Kury. 5a ed. Rio de Janeiro: Jorge Zahar, 2000.

KANT, Immanuel. Crítica da razão pura. Tradução: Manuela Pinto Dos Santos e Alexandre Fradique Morujão. $5^{\text {a }}$ ed. Lisboa: Fundação Calouste Gulbenkian, 2001.

MACHADO, Roberto. Nietzsche e a verdade. $2^{\mathrm{a}}$ ed. Rio de Janeiro: Rocco, 1985.

NIETZSCHE. Sämtlich Werke. Kritische Studienausgabe. G. Colli und M. Montinari (Hg). Berlin: Walter de Gruyter, 1999. 15 Baden.

O nascimento da tragédia. Tradução: Jacó Guinsburg. São

Paulo: Companhia das Letras, 1992.

RUBIRA, Luís. Nietzsche: da tragédia grega à filosofia trágica. Dissertatio, Pelotas, [29], p. 249-261, inverno de 2009.

SCHELLING. Filosofia da arte. Tradução: Márcio Suzuki. São Paulo: EDUSP, 2001.

SÓFOCLES. Édipo Rei. Tradução: Agostinho da Silva. $7^{a}$ ed. Lisboa: Editorial Inquérito, S/D.

VATTIMO, Gianni. El sujeito y la Máscara. Tradução: Jorge Binagui. Barcelona: Provença, 1989. 